Article

\title{
Fast Coordinated Control of DFIG Wind Turbine Generators for Low and High Voltage Ride-Through
}

\author{
Yun Wang ${ }^{1,6}$, Qiuwei Wu ${ }^{2,5, *}$, Honghua $\mathrm{Xu}^{3}$, Qinglai Guo ${ }^{4}$ and Hongbin Sun ${ }^{4}$
}

1 College of Mechatronics and Control Engineering, Shenzhen University, Shenzhen 518060, Guangdong, China; E-Mail: wangyun@szu.edu.cn

2 Centre for Electric Power and Energy, Department of Electrical Engineering, Technical University of Denmark, Elektrovej 325, Kgs. Lyngby 2800, Denmark

3 Institute of Electrical Engineering, Chinese Academy of Sciences, Beijing 100190, China; E-Mail: hxu@mail.iee.ac.cn

4 Department of Electrical Engineering, Tsinghua University, Beijing 100084, China; E-Mails: guoqinglai@tsinghua.edu.cn (Q.G.); shb@mail.tsinghua.edu.cn (H.S.)

5 State Key Lab of Power System, Department of Electrical Engineering, Tsinghua University, Beijing 100084, China

6 Shenzhen Key Laboratory of Urban Rail Transit, Shenzhen University, Shenzhen 518060 , Guangdong, China

* Author to whom correspondence should be addressed; E-Mail: qw@elektro.dtu.dk; Tel.: +45-452-535-29; Fax: +45-458-861-11.

Received: 20 May 2014; in revised form: 21 June 2014 / Accepted: 22 June 2014 /

Published: 27 June 2014

\begin{abstract}
This paper presents a fast coordinated control scheme of the rotor side converter (RSC), the Direct Current (DC) chopper and the grid side converter (GSC) of doubly fed induction generator (DFIG) wind turbine generators (WTGs) to improve the low voltage ride through (LVRT) and high voltage ride through (HVRT) capability of the DFIG WTGs. The characteristics of DFIG WTGs under voltage sags and swells were studied focusing on the DFIG WTG stator flux and rotor voltages during the transient periods of grid voltage changes. The protection schemes of the rotor crowbar circuit and the DC chopper circuit were proposed considering the characteristics of the DFIG WTGs during voltage changes. The fast coordinated control of RSC and GSC were developed based on the characteristic analysis in order to realize efficient LVRT and HVRT of the DFIG WTGs. The proposed fast coordinated control schemes were verified by time domain simulations using Matlab-Simulink.
\end{abstract}


Keywords: coordinated control; doubly-fed induction generator (DFIG); grid side converter (GSC); high voltage ride through (HVRT); low voltage ride through (LVRT); rotor side converter (RSC)

\section{Introduction}

The doubly fed induction generator (DFIG) is one of the most popular types of generators used in large scale wind turbines with several advantages compared to other wind turbine generators (WTGs) [1]. However, because the stator windings are directly connected to the grid, DFIG WTGs are quite sensitive to grid disturbances. In the past, WTGs were allowed to disconnect from the grid during low voltage conditions. However, with the rapidly increased penetration of wind power and concentrated wind power installation, disconnection of WTGs due to low voltage conditions can cause serious problems on the power system stability. After the low voltage fault is cleared, high voltage conditions may be induced if there is no fast automatic control of the reactive power, and more wind turbines will be tripped due to the high voltage conditions. Many grid codes require wind power plants (WPPs) to remain connected to the grid during low or high voltage conditions, referred to as low voltage ride through (LVRT) or high voltage ride through (HVRT) requirements [2,3].

In recent studies, the characteristics of voltage sags at the point of common coupling (PCC) of WPPs are studied with consideration of grid-angel jumps [4-7]. In [6,7], the effects of phase-angel jump on transient DFIG operation are discussed, and it is shown that large phase-angel jumps have significant impacts on DFIG transient behaviour. These studies are based on the voltage divider model with different $X / R$ ratios of impedance and the detailed discussion is focused on the amplitude of the fault voltage and grid-fault angel. However, the overvoltage conditions during the voltage recovery period have not been investigated.

The transient behaviour of DFIG WTGs under grid fault conditions has been comprehensively investigated by analysing the transient electromagnetic force characteristic of stator flux [8-12], and the oscillating response of the DC link voltage was studied in [13,14]. Many solutions have been proposed to solve the LVRT problem for DFIGs, which can be categorized into two types including "the crowbar protection method" and "the demagnetizing method". An additional hardware crowbar circuit with resistors can protect the rotor side converter (RSC) from rotor overcurrent [15-17]. A similar circuit called 'DC-chopper' is used to protect the DC link from overvoltage $[18,19]$. However, the existing methods have not considered the voltage swell faults under phase-angel jump conditions. In addition to the hardware solutions, many control strategies have been developed for improving the transient response performance of DFIG WTGs under grid voltage sags [20-22]. However, most methods have not considered that the converter capacity limitations can influence the DC-overvoltage especially for HVRT and are difficult to implement without considering the phase-angel jump.

This paper aims to further analyse the transient response of DFIG WTGs with consideration of phase-angel jumps under both grid voltage sags and swells. A rotor crowbar protection scheme used for voltages sag or swell is developed, and a new DC chopper protection scheme coordinated with the active power of the RSC and grid side converter (GSC) is proposed, which can prevent DC links from 
overvoltage and voltage oscillation. A voltage assessment method considering phase-angel jumps is used in this paper, and the amplitude of the fault voltage and the phase angel for vector control of converters can be obtained correctly. The transient stator flux compensation component is used as feed-forward factor for the vector control, which can improve the transient performance of the RSC controller. In order to keep the DC voltage under the maximum threshold during the grid voltage swell, a reactive current control scheme of the GSC is proposed in this paper. Case studies using Matlab-Simulink (The MathWorks, Natick, MA, USA) have been conducted in order to verify the effectiveness of the proposed protection schemes and control strategies.

The paper is organized as follows: the analysis of the grid fault conditions is described in Section 2. The behavior of the DFIG WTG and GSC under voltage sag and swell conditions is discussed in Section 3. The protection schemes of DFIGs for fault ride through (FRT) are explained in Section 4 and the enhanced GSC and RSC control of DFIGs is presented in Section 5. The case studies are described and discussed in Section 6. Finally, the conclusions are drawn.

\section{Analysis of Grid Fault Conditions}

This section analyzes both grid voltage sag and swell fault conditions at the point of common coupling (PCC) of a wind farm. The voltage-divider model is widely used in the analysis of characteristics of grid faults in radial systems [4-7] and is used for the grid voltage sag and swell fault conditions at the PCC of a wind farm.

Figure 1 shows the voltage-divider model with the impedance between the wind farm and the fault location where $\boldsymbol{V}_{\mathrm{s}}$ is the pre-fault voltage, $\boldsymbol{Z}_{1}$ is the impedance between the wind farm and the fault location, $\boldsymbol{Z}_{2}$ is the impedance between the grid connection point (GCP) and the fault location, and $\boldsymbol{Z}_{\mathrm{f}}$ is the impedance between the fault location and ground. In the voltage-divider model, the wind farm current before as well as during the fault is neglected [4]. The voltage at the PCC during grid faults can then be defined as:

$$
V_{\text {sag }}=\frac{Z_{\mathrm{f}}}{Z_{\mathrm{f}}+Z_{2}} V_{\mathrm{s}}
$$

where $V_{\text {sag }}$ is the voltage at the PCC during the fault.

Figure 1. Voltage-divider model.

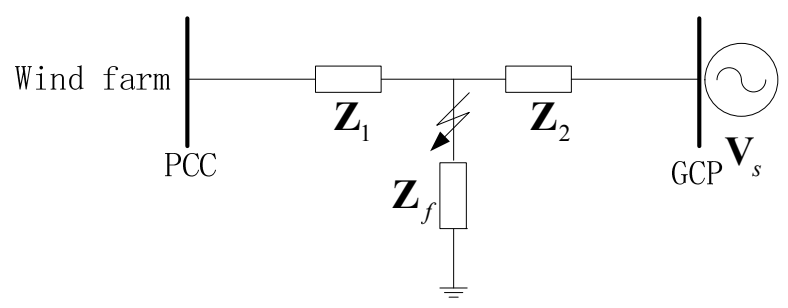

The sum of $\boldsymbol{Z}_{1}$ and $\boldsymbol{Z}_{2}$ is the equivalent impedance of the external grid and can be defined as $\boldsymbol{Z}_{\mathrm{s}}$ which can be expressed as:

$$
Z_{\mathrm{s}}=\frac{\left|V_{\mathrm{s}}\right|^{2}}{k \cdot S} e^{j \alpha_{\mathrm{s}}}
$$


where $\alpha_{\mathrm{s}}$ is the impedance angel of $Z_{\mathrm{s}}$, and $S$ is the installed capacity of the wind farm, and $k$ is the ratio of the system strength to the wind farm installed capacity. Define $p$ as the ratio of the distance between the fault location and the PCC to the distance between the PCC and the GCP, and consider $\boldsymbol{Z}_{\mathrm{s}}$ is linear by step on the transmission line, $\boldsymbol{Z}_{2}$ can be expressed as:

$$
Z_{2}=p Z_{\mathrm{s}}=\frac{p\left|V_{\mathrm{s}}\right|^{2}}{k \cdot S} e^{j \alpha_{\mathrm{s}}}
$$

Similarly, by defining $q$ as the ratio of $\boldsymbol{Z}_{\mathrm{f}}$ to $\boldsymbol{Z}_{\mathrm{s}}$, which depends on the fault location, $\boldsymbol{Z}_{\mathrm{s}}$ and $\boldsymbol{Z}_{\mathrm{f}}$ have the following relation:

$$
\frac{Z_{\mathrm{f}}}{Z_{2}}=\frac{q}{p} e^{j\left(\alpha_{\mathrm{f}}-\alpha_{\mathrm{s}}\right)}=\lambda e^{j \alpha}
$$

where $\alpha_{\mathrm{f}}$ is the impedance angel of $\boldsymbol{Z}_{2}, \lambda$ represents the relative fault distance, and $\alpha$ is fixed for any given source [4], such as $0^{\circ}$ (the most common value for transmission systems), $-20^{\circ}$ (typical value for distribution systems), or $-60^{\circ}$ (the minimum value for wind farms located offshore with submarine alternating current (AC) cables). Using Equations (1) and (4), the voltage at the PCC during grid faults can be obtained as follows:

$$
V_{\mathrm{sag}}=\frac{\lambda e^{j \alpha}}{1+\lambda e^{j \alpha}} V_{\mathrm{s}}
$$

\subsection{Symmetrical Voltage Sag Fault}

It is shown from Equation (2) to Equation (5) that $\boldsymbol{V}_{\text {sag }}$ depends on $\lambda$ and $\alpha$. For voltage sags under symmetrical fault conditions (Type A), Figure 2 shows the voltage magnitude and phase-angel jump with respect to the change of $\lambda$ or $\alpha$.

Figure 2. Magnitude and phase-angel jump under grid fault Type A. (a) $\alpha$ is fixed; (b) $\lambda$ is fixed.
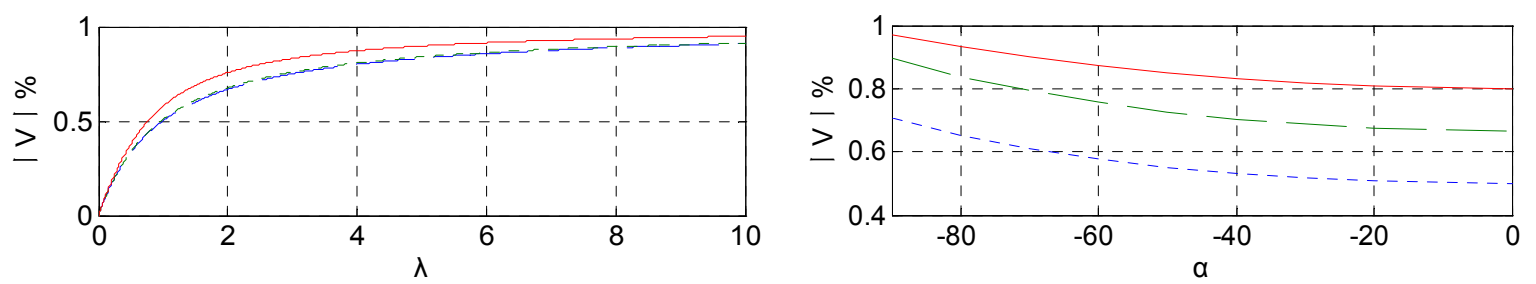

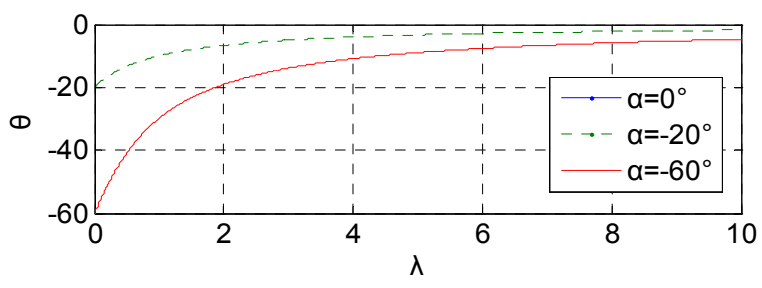

(a)

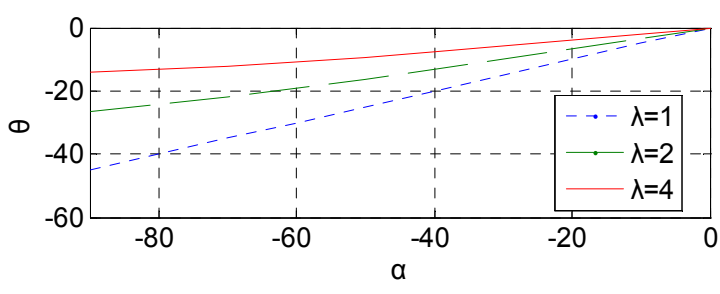

(b)

It is shown in Figure 2a, with the same impedance angel $\alpha$, both fault depth (1-magnitude of fault voltage) and phase-angel jump decreases as $\lambda$ increases; it is shown in Figure $2 b$, with the same relative fault distance $\lambda$, phase-angel jump decreases as $|\alpha|$ decreases (when $\alpha=0^{\circ}$, no phase-angel jump), however, decreasing $|\alpha|$ will increase fault depth. 


\subsection{Voltage Swell Condition}

There are many situations causing voltage swells in the grid, such as load shedding or unbalanced grid faults. According to the analysis of the data from the fault recorders, voltage swells may occur during the low voltage fault recovery period. The cascading wind turbine tripping in China shows that the large scale wind turbine tripping was initially triggered by a low voltage condition caused by an electric component phase to phase fault and quite a number of wind turbines tripped. After the fault was cleared, high voltage condition was induced because there was no automatic control of reactive power compensation within WPPs and more wind turbines tripped due to the over-voltage conditions.

The resulting over-voltage condition may have different magnitudes and durations, depending on the disturbance. Similar to the grid voltage dip analysis results, overshoot of amplitude and phase-angel jump may occur during the voltage recovery, depending on the impedance angel $\alpha$, the relative fault distance $\lambda$, the type and capacity of reactive power compensation equipment.

\section{Behavior of DFIG WTG and GSC under Voltage Sag and Swell}

This section is to analyze the dynamic responses of the DFIG WTG and GSC under voltage sag and swell conditions, and evaluate the impact on both the RSC and the GSC.

\subsection{DFIG Model and GSC Model}

Figure 3a shows the " $\Gamma$-form" equivalent circuit of a DFIG following the motor direction. The stator- and rotor-side vectors in the stator reference frame with all the parameters converted to the stator are:

$$
\left\{\begin{array}{l}
\vec{v}_{\mathrm{s}}^{\mathrm{s}}=R_{\mathrm{s}} \vec{i}_{\mathrm{s}}^{\mathrm{s}}+\frac{d \vec{\psi}_{\mathrm{s}}^{\mathrm{s}}}{d t} \\
\vec{v}_{\mathrm{r}}^{\mathrm{s}}=R_{\mathrm{r}} \vec{i}_{\mathrm{r}}^{\mathrm{s}}+\frac{d \vec{\psi}_{\mathrm{r}}^{\mathrm{s}}}{d t}+j \omega_{\mathrm{r}} \vec{\psi}_{\mathrm{r}}^{\mathrm{s}}
\end{array}\right.
$$

where $\omega_{\mathrm{r}}$ is the rotor speed, and subscripts $s$ and $r$ indicate stator and rotor.

Figure 3. Equivalent circuit of: (a) DFIG from the stator side; (b) DC link; and (c) External grid.

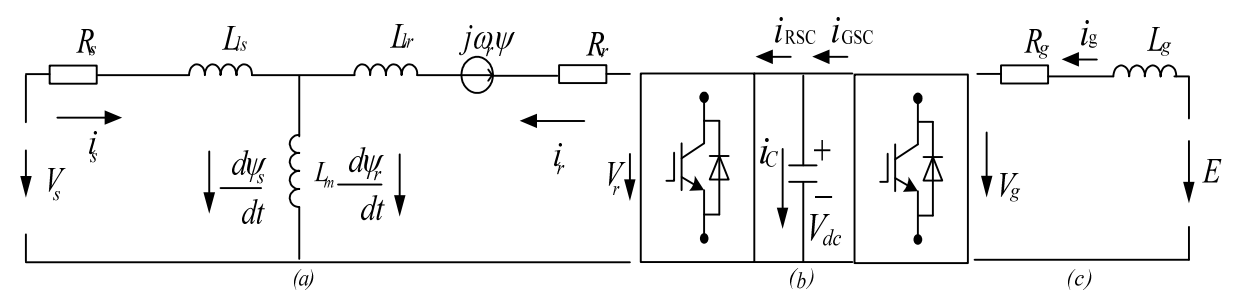

The flux linkage equations of the stator and rotor are:

$$
\left\{\begin{array}{l}
\vec{\psi}_{\mathrm{s}}=L_{\mathrm{s}} \vec{i}_{\mathrm{s}}+L_{\mathrm{m}} \vec{i}_{\mathrm{r}} \\
\vec{\psi}_{\mathrm{r}}=L_{\mathrm{m}} \vec{i}_{\mathrm{s}}+L_{\mathrm{r}} \vec{i}_{\mathrm{r}}
\end{array}\right.
$$

where $L_{\mathrm{s}}, L_{\mathrm{r}}$ and $L_{\mathrm{m}}$ are the stator inductance, rotor inductance and mutual inductance, respectively. 
Using Equations (6) and (7), the rotor voltage vector and the stator flux are obtained as Equations (8) and (9):

$$
\begin{gathered}
\vec{v}_{\mathrm{r}}=\frac{L_{\mathrm{m}}}{L_{\mathrm{s}}}\left(\frac{d}{d t}-j \omega_{\mathrm{r}}\right) \vec{\psi}_{\mathrm{s}}+\left(R_{\mathrm{r}}-\sigma L_{\mathrm{r}}\left(\frac{d}{d t}-j \omega_{\mathrm{r}}\right)\right) \vec{i}_{\mathrm{r}} \\
\frac{d \vec{\psi}_{\mathrm{s}}}{d t}=\vec{V}_{\mathrm{s}}-\frac{R_{\mathrm{s}}}{L_{\mathrm{s}}} \vec{\psi}_{\mathrm{s}}+\frac{R_{\mathrm{s}} L_{\mathrm{m}}}{L_{\mathrm{s}}} \vec{i}_{\mathrm{r}}
\end{gathered}
$$

where $\sigma=1-L_{\mathrm{m}}{ }^{2} / L_{\mathrm{s}} \cdot L_{\mathrm{r}}$ is the linkage coefficient.

It is shown from Equation (8) that the rotor voltage can be decomposed into two parts (the electromotive force (EMF) and the voltage drop caused by rotor current) [8].

Figure $3 \mathrm{~b}$ shows the circuit of DC link. The equation of the DC link voltage is:

$$
C \frac{d \vec{v}_{\mathrm{dc}}}{d t}=\vec{i}_{\mathrm{GSC}}-\vec{i}_{\mathrm{RSC}}
$$

Figure 3c shows the grid side equivalent circuit. Neglecting the line side resistance $R_{\mathrm{g}}$, the terminal voltage of the GSC is:

$$
\vec{v}_{\mathrm{g}}=\vec{E}-L_{\mathrm{g}} \frac{d \vec{i}_{\mathrm{g}}}{d t}-j \omega_{\mathrm{s}} L_{\mathrm{g}} \vec{i}_{\mathrm{g}}
$$

where $L_{\mathrm{g}}$ is the line side inductance of the GSC. In the voltage oriented reference frame, the d- and q-components of the GSC voltage are:

$$
\left\{\begin{array}{l}
v_{\mathrm{gd}}=E_{\mathrm{gd}}-L_{\mathrm{g}} \frac{d i_{\mathrm{gd}}}{d t}+\omega_{\mathrm{s}} L_{\mathrm{g}} i_{\mathrm{gq}} \\
v_{\mathrm{gq}}=-L_{\mathrm{g}} \frac{d i_{\mathrm{gq}}}{d t}-\omega_{\mathrm{s}} L_{\mathrm{g}} i_{\mathrm{gd}}
\end{array}\right.
$$

\subsection{Behavior of the DFIG WTG under Voltage Sag Condition}

Considering the magnitude of the DFIG parameters (about $10^{-3}$ ), the last part of Equation (9) can be neglected, then Equation (9) is simplified as a first-order differential equation to the stator flux, and the boundary condition is:

$$
\vec{\psi}_{\mathrm{s}}\left(t_{0}^{-}\right)=\vec{\psi}_{\mathrm{s}}\left(t_{0}^{+}\right)
$$

where $t_{0}$ is the moment when voltage sag or jump occurs. The solution of Equation (9) is obtained as:

$$
\vec{\psi}_{\mathrm{s}_{-} \mathrm{dc}}=\frac{V_{\mathrm{s} \_\mathrm{dc}}}{j \omega_{\mathrm{s}}} e^{-\frac{\mathrm{t}}{\tau}}
$$

where $\tau=L_{\mathrm{S}} / R_{\mathrm{S}}$ is the time constant of the stator flux, $\omega_{\mathrm{s}}$ is the stator angular frequency, and $V_{\mathrm{s} \_ \text {dc }}$ is derived by Equation (10), which is a DC component and excited only during the dynamic operation. During normal operation, neglecting the stator resistance, the stator flux can be expressed as follows:

$$
\vec{\psi}_{\mathrm{s} \_ \text {ac }}=\frac{V_{\mathrm{s}}}{j \omega_{\mathrm{s}}} e^{\mathrm{j} \omega_{\mathrm{s}} \mathrm{t}}
$$

In the analysis, the flux imposed by the stator voltage can be calculated by Equations (11) and (12): 


$$
\vec{\psi}_{\mathrm{s}}=\vec{\psi}_{\mathrm{s} \_\mathrm{ac}}+\vec{\psi}_{\mathrm{s} \_\mathrm{dc}}=(1-P) \frac{V_{\mathrm{s}}}{j \omega_{\mathrm{s}}} e^{j\left(\omega_{\mathrm{s}} \mathrm{t}+\theta\right)}+\frac{V_{\mathrm{s}}\left[e^{j \omega_{\mathrm{s}} \mathrm{t}_{0}}-(1-P) e^{j\left(\omega_{\mathrm{s}} \mathrm{t}_{0}+\theta\right)}\right]}{j \omega_{\mathrm{s}}} e^{-\frac{\mathrm{t}}{\tau}}
$$

where $P$ is the depth of the voltage sag or swell, $\theta$ is the phase-angel jumps of the voltage.

In Figure $4 \mathrm{a}, \mathrm{b}$, it is shown that the dynamic response of the DFIG and the DC link voltage is independent of the voltage phase when faults occur. With the phase-angel jump increasing, the overshoots of the rotor flux and the rotor current increases, as Figure $4 \mathrm{c}$ shows. By solving Equations (8) and (16), the rotor voltage in the rotor frame is:

$$
\vec{v}_{\mathrm{r}}^{r}=\vec{v}_{\mathrm{r} 0}^{r}+R_{\mathrm{r}} \vec{i}_{\mathrm{r}}^{r}+\sigma L_{\mathrm{r}} \frac{d \vec{i}_{\mathrm{r}}^{r}}{d t}
$$

Where $\vec{v}_{\mathrm{r} 0}^{r}$ is the EMF part:

$$
\vec{v}_{\mathrm{r} 0}^{\mathrm{r}}=\frac{L_{\mathrm{m}}}{L_{\mathrm{s}}}\left[s V_{\mathrm{s}}(1-P) e^{\mathrm{j}\left(\omega_{\mathrm{s}} \mathrm{t}+\theta\right)}-\left(\frac{1}{\tau}+(1-s) j \omega_{\mathrm{s}}\right) \vec{\psi}_{\mathrm{s}_{-} \mathrm{dc}} e^{-\mathrm{j} \omega_{\mathrm{r}} \mathrm{t}}\right]
$$

Figure 4. Simulation results for three-phase faults ( 0.5 p.u.) with different voltage phase when faults occur and phase-angel jumps (a) phase angel jump $\theta=0^{\circ}, \omega t=k \pi$; (b) phase angel jump $\theta=0^{\circ}, \omega t=(k+0.25) \pi$; and (c) phase angel jump $\theta=60^{\circ}, \omega t=k \pi$.
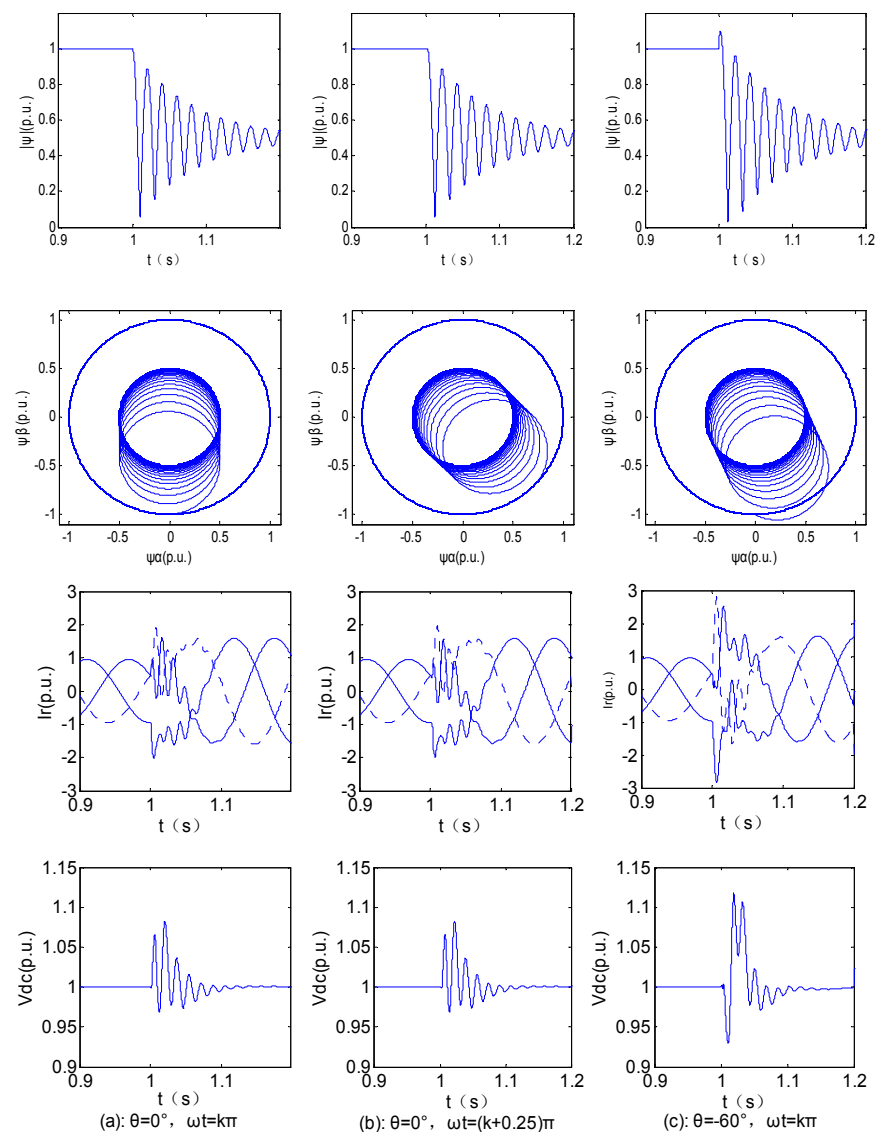

Under a severe situation $(P=1, \theta=0)$, for example, before and after the fault occurs, the aptitude of $V_{\mathrm{r} 0}$ changes from $\left[L_{\mathrm{m}} \cdot V_{\mathrm{s}} \cdot|s| / L_{\mathrm{s}}\right]$ to $\left[L_{\mathrm{m}} \cdot(1-s) \cdot V_{\mathrm{s}} / L_{\mathrm{s}}\right]$ according to Equation (18). Assuming $s=0.3$, the overvoltage value of $V_{\mathrm{r} 0}$ is 2.3 times of the nominal value, and it is 4.3 times assuming $s=-0.3$. The results show that when grid faults occur, a large rotor voltage is required to control the rotor current. 
Since the performance of the RSC controller is restricted by its capability, the rotor current cannot follow such a reference, which leads to over current, and then the over current protection of the RSC is activated. Since the active power output of the GSC is substantially reduced after a grid fault, a large quantity of energy from the RSC flows into the DC link which causes the DC voltage to increase and oscillate.

\subsection{Behavior of the DFIG WTG under Voltage Swell Conditions}

Figure 5 shows the simulation results considering the voltage magnitude and the phase-angel jump during the grid fault recovery. It is shown that the operating characteristics of the DFIG WTG under voltage swells are similar to those under voltage sags. However, after the transient oscillation, the DC voltage increases up to a high value because the line side voltage exceeds the maximum voltage of the GSC, which is:

$$
\left|v_{\text {glrms,max }}\right|=M v_{\mathrm{dc}}
$$

where $M$ is the maximum voltage utilization. The minimum value of $v_{\mathrm{dc}}$ is determined by $M$ and $\left|v_{\text {glrms }}\right|$ $(M=\sqrt{2}$ for SVPWM; $=2 \sqrt{2} / \sqrt{3}$ for SPWM; and $=1.35$ for diode rectification, which is the minimum limitation). Based on Equation (19), the minimum DC voltage value increases with the high grid voltage, which may exceed the maximum controllable DC voltage range of the GSC, and lead to continuous overvoltage of the DC link during the whole process of the high voltage condition.

Figure 5. Simulation results for three-phase faults (1.3 p.u.) with different voltage phases when faults and phase-angel jump occur (a) phase angel jump $\theta=0^{\circ}, \omega t=k \pi$; (b) phase angel jump $\theta=0^{\circ}, \omega t=(k+0.25) \pi$; and (c) phase angel jump $\theta=60^{\circ}, \omega t=k \pi$.
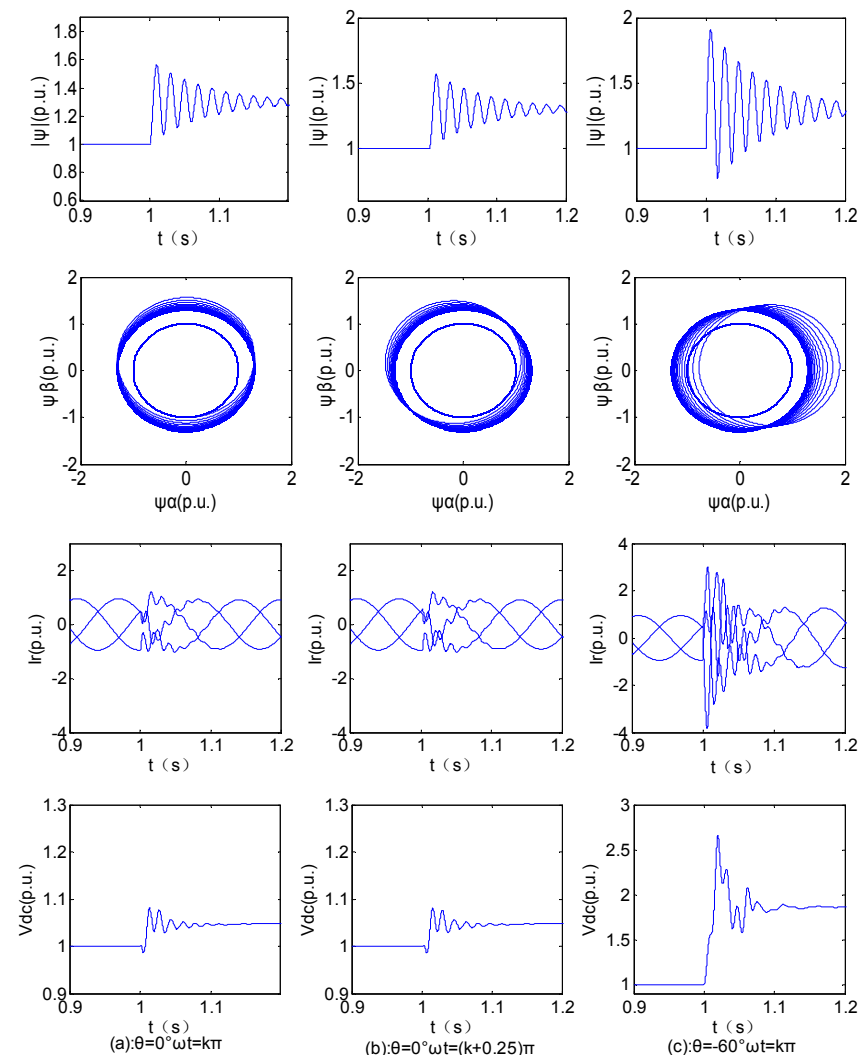


\section{Protection Schemes of the DFIG WTG for Fault Ride Through}

It is known from the above section that the overcurrent on rotor windings and overvoltage at the DC link occurs during the grid voltage sags or swells. In order to protect the WTG and keep it stay connected to the grid under the grid code specified low voltage or high voltage conditions, the protection schemes of the DFIG WTG with active crowbar and DC chopper circuits are described in this section. The structure of the protection schemes is illustrated in Figure 6.

Figure 6. DFIG WTG model with protection schemes.

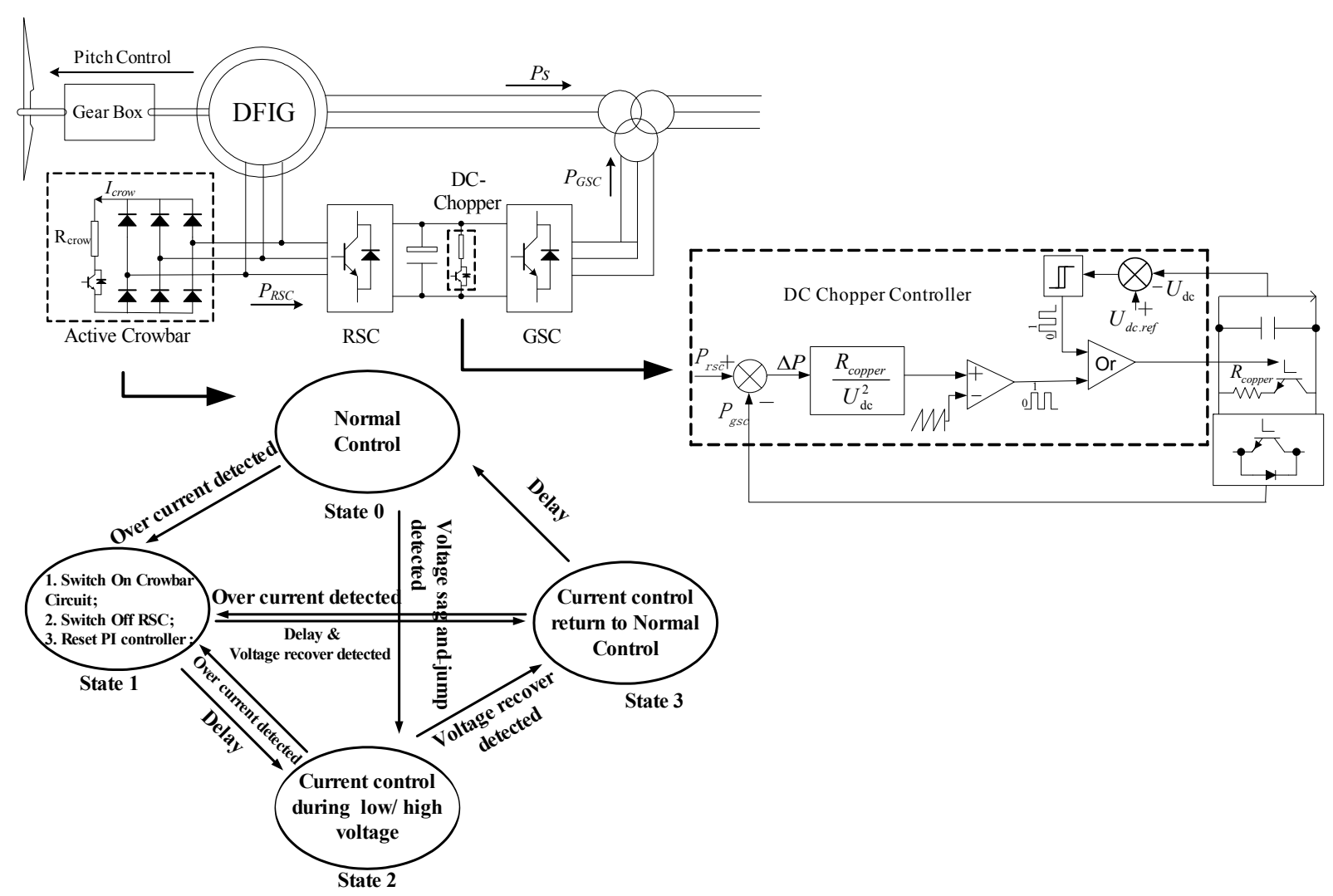

\subsection{Active Crowbar Protection Scheme}

In order to realize HVRT/LVRT, a set of control logics of the crowbar circuit has been developed and is shown in Figure 6 based on the finite state machine design method. Whether the crowbar is to be activated depends on the flag of the overcurrent detection. The overcurrent threshold is usually 1.5 to 2.5 times the rated value. As shown in State 1, with the crowbar circuit "switched on" and the RSC "switched off", the integration of the rotor current PI controller should be reset, and the reference value should be set as the feedback value, which is to avoid the saturation of the Proportional Integral (PI) controller. Considering the short grid reclosing time $(0.15 \mathrm{~s}$ to $0.5 \mathrm{~s})$ and the response of the automatic throw-in equipment for emergency power supply $(0.2 \mathrm{~s}$ to $0.5 \mathrm{~s})$, the recovery delay is set from state 3 (current control) to state 4 (normal control). For the current control of the RSC during the low or high grid voltage conditions, it is required to rapidly detect the depth of voltage sag or swell. Considering asymmetric characteristics and phase-angel jump of actual grid faults, a fast detection method base on the second-order generalized integrator is used and is shown in Figure 7. 
Figure 7. Scheme of grid fault detection method.

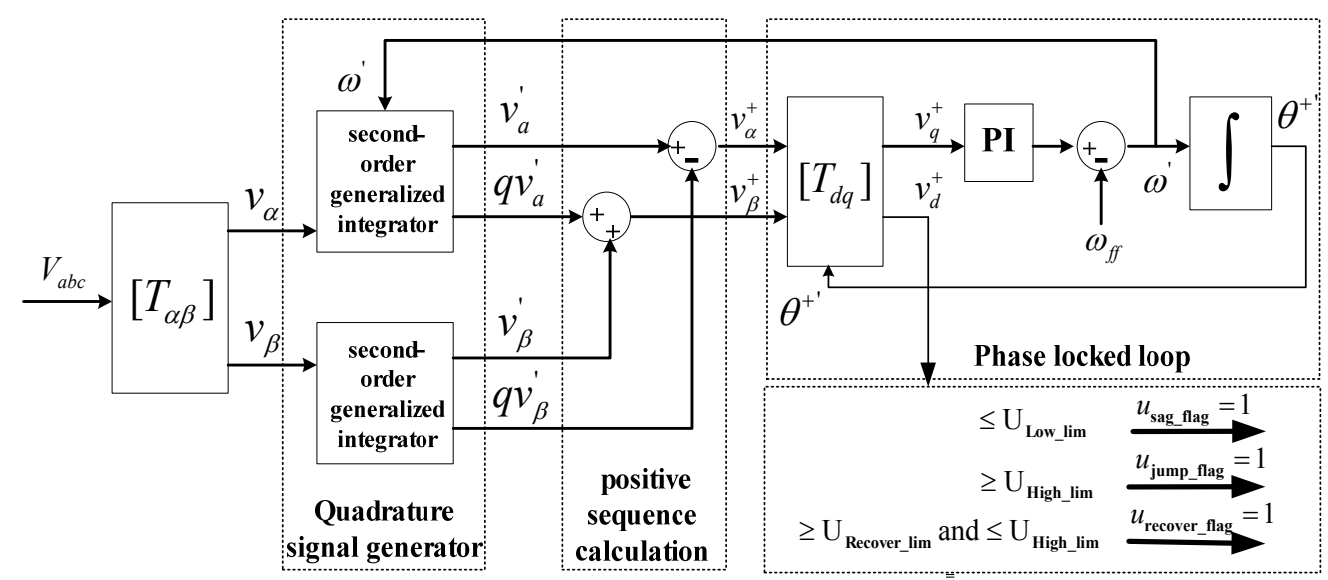

After filtering with the second-order generalized integrator, $v_{\alpha} / \mathrm{v}_{\beta}$ and its orthogonal signal $q v_{\alpha} / q \mathrm{v}_{\beta}$ are obtained, where $q$ is the signal delayed $T_{\mathrm{S}} / 4\left(=e^{-j \frac{\pi}{2}}\right)$, so the positive voltage can be calculated as:

$$
\begin{aligned}
& v_{\alpha}^{+}=\frac{1}{2} v_{\alpha}-\frac{q}{2} v_{\beta} \\
& v_{\beta}^{+}=\frac{q}{2} v_{\alpha}+\frac{1}{2} v_{\beta}
\end{aligned}
$$

The transfer functions of the second-order generalized integrator are:

$$
\begin{aligned}
& D(s)=\frac{v^{\prime}}{v}(s)=\frac{k \omega s}{s^{2}+k \omega s+\omega^{2}} \\
& Q(s)=\frac{q v^{\prime}}{v}(s)=\frac{k \omega^{2}}{s^{2}+k \omega s+\omega^{2}}
\end{aligned}
$$

where $\omega$ is the resonance frequency and $k$ is the damping ratio. Figure 8 shows the performance of this method simulated by Matlab-Simulink, and it can be seen when grid voltage jump to 1.3 p.u. with phase-angel jump to $-60^{\circ}$ at $0.1 \mathrm{~s}$, the positive sequence voltage and phase angel can be calculated in $T_{\mathrm{s}} / 4$.

\subsection{Chopper Control Scheme}

A chopper circuit with a resistor is added to reduce the overvoltage and voltage-fluctuation of the DC-link during grid voltage sags and swells, and Figure 6 shows its control scheme. As seen from Equation (10), the reason of the DC-voltage fluctuation is the unbalanced current from the RSC and the GSC. Neglecting the power losses of the converters and considering the active power negligible flowing into the grid, Equation (10) can be expressed as:

$$
\frac{1}{2} C \frac{d V_{\mathrm{dc}}^{2}}{d t}=P_{\mathrm{GSC}}-P_{\mathrm{RSC}}
$$

Based on Equation (22), during the grid disturbance, by dissipating the extra energy into the resistor of the DC chopper, the fluctuation of the DC voltage can be reduced, so the duty of the DC-chopper switch is derived as:

$$
D=\frac{R_{\mathrm{dc} \_ \text {chopper }}}{V_{\mathrm{dc}}^{2}}\left(P_{\mathrm{GSC}}-P_{\mathrm{RSC}}\right)
$$


It is shown in Figure 6, the IGBT of the DC chopper is activated in order to balance the active power between the grid side and the rotor side based on Equation (23), and it is also triggered when the DC voltage exceeds its limitation, which is to protect the DC capacitor from over-voltage especially during HVRT.

Figure 8. Simulation results for grid voltage detection method (positive sequence magnitude: 1.3 p.u.; negative sequence aptitude: 0.3 p.u.; positive sequence phase-angel jump: $-60^{\circ}$; negative sequence phase-angel jump: $0^{\circ}$ ). (a) three phase grid voltages; (b) the positive amplitude value of grid voltage; (c) the angel of gird voltage; and (d) the positive components of three phase gird voltages.

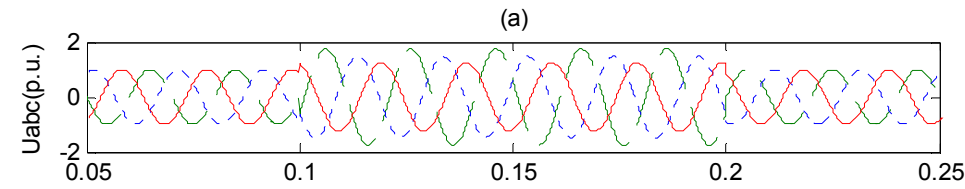

(b)

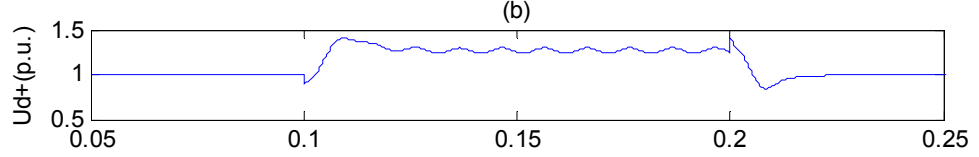

(c)
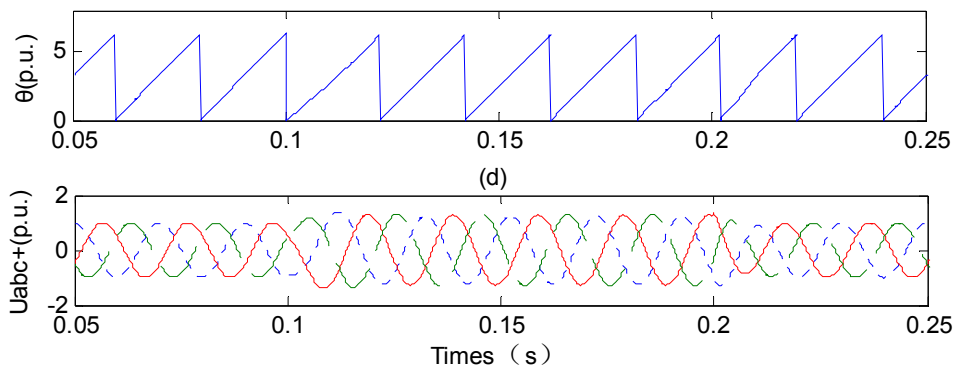

\section{Enhanced Control of RSC and GSC for LVRT and HVRT}

As illustrated in section III, the difficulty of the LVRT/HVRT control of the RSC is the uncontrolled transient over current on the rotor side of the DFIG caused by the transient EMF part of the stator flux, and the over voltage and fluctuation of the DC link. This section is focused on the enhanced feedback control of the RSC and the GSC to improve the dynamic performance of rotor current and DC voltage, and enhance the LVRT/HVRT capability by reactive power control. The control scheme diagram is shown in Figures 9 and 10.

Figure 9. Enhanced control of the GSC.

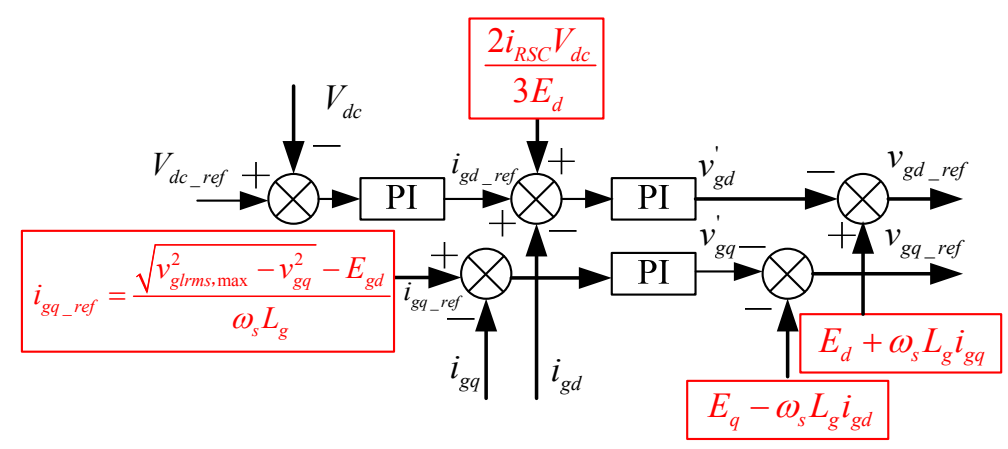


Figure 10. Enhanced control of the RSC.

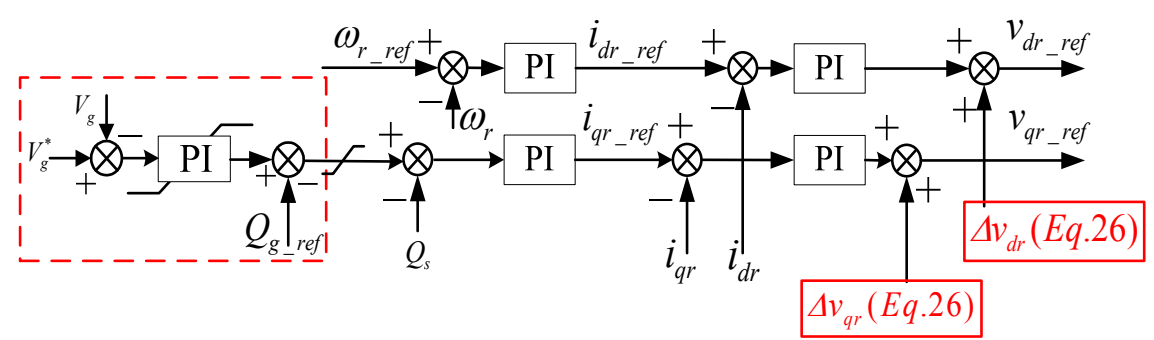

\subsection{Enhanced RSC Control}

During the normal operation, with a reference frame oriented along with the stator flux vector by the vector control technique, the active power and reactive power are decoupled by controlling $d$ - and $q$-axis components of the rotor current [16]. The steady state mathematical model is commonly used for the DFIG controller design, in which the transient part of the stator flux is neglected, and the stator flux is calculated by the voltage model observer method. The rotor voltage vector is expressed as:

$$
\left\{\begin{array}{l}
v_{\mathrm{dr}}=\underbrace{R_{\mathrm{r}} i_{\mathrm{dr}}+\sigma L_{\mathrm{r}} \frac{\mathrm{d} i_{\mathrm{dr}}}{\mathrm{d} t}}_{P I} \underbrace{-\omega_{\text {slip }} \sigma L_{\mathrm{r}} i_{\mathrm{qr}}}_{\text {feedforward -factor }} \\
v_{\mathrm{qr}}=\underbrace{R_{\mathrm{r}} i_{\mathrm{qr}}+\sigma L_{\mathrm{r}} \frac{\mathrm{d} i_{\mathrm{qr}}}{\mathrm{d} t}}_{P I} \underbrace{\omega_{\text {slip }}\left(\frac{L_{\mathrm{m}}}{L_{\mathrm{s}}} \frac{V_{\mathrm{s}}}{\omega_{\mathrm{s}}}+\sigma L_{\mathrm{r}} i_{\mathrm{dr}}\right)}_{\text {feedforward-factor }}
\end{array}\right.
$$

where the first part is used for $d$ - and $q$-axis rotor current inner closed-loop PI controller, and the second part is added as the feed-forward term of the current inner closed-loop. However, when grid fault or voltage jump occurs, as illustrated in Section 3, a transient decaying oscillation EMF component of the rotor voltage is excited, therefore, the feed-forward terms of the current controller should reflect the transient characteristic of the rotor voltage excited by the dynamic change of the stator flux. Based on Equation (8), the enhanced $d$ - and $q$-axis components of the rotor voltage vector can be expressed as:

$$
\left\{\begin{array}{l}
v_{\mathrm{dr}}=\underbrace{R_{\mathrm{r}} i_{\mathrm{dr}}+\sigma L_{\mathrm{r}} \frac{\mathrm{d} i_{\mathrm{dr}}}{\mathrm{d} t}}_{P I} \underbrace{-\omega_{\mathrm{slip}}\left(\frac{L_{\mathrm{m}}}{L_{\mathrm{s}}} \psi_{\mathrm{sq}}+\sigma L_{\mathrm{r}} i_{\mathrm{qr}}\right)+\frac{L_{\mathrm{m}}}{L_{\mathrm{s}}} \frac{d \psi_{\mathrm{sd}}}{d t}}_{\text {feedforward-factor }} \\
v_{\mathrm{qr}}=\underbrace{R_{\mathrm{r}} i_{\mathrm{qr}}+\sigma L_{\mathrm{r}} \frac{\mathrm{d} i_{\mathrm{qr}}}{\mathrm{d} t}}_{P I} \underbrace{+\omega_{\text {slip }}\left(\frac{L_{\mathrm{m}}}{L_{\mathrm{s}}} \psi_{\mathrm{sd}}+\sigma L_{\mathrm{r}} i_{\mathrm{dr}}\right)+\frac{L_{\mathrm{m}}}{L_{\mathrm{s}}} \frac{d \psi_{\mathrm{sq}}}{d t}}_{\text {feedforward-factor }}
\end{array}\right.
$$

where the feed forward elements can be derived from Equation (9) by the voltage model observer neglecting the rotor resistance and are as follows:

$$
\left\{\begin{array}{l}
\Delta v_{\mathrm{dr}}=\frac{L_{\mathrm{m}}}{L_{\mathrm{s}}}\left(V_{\mathrm{s}}-R_{\mathrm{s}} i_{\mathrm{ds}}\right)+\omega_{\mathrm{r}} L_{\mathrm{m}} i_{\mathrm{qs}}-\left[\omega_{\mathrm{slip}} L_{\mathrm{r}}-\omega_{\mathrm{s}} \frac{L_{\mathrm{m}}^{2}}{L_{\mathrm{s}}}\right] i_{\mathrm{qr}} \\
\Delta v_{\mathrm{qr}}=-\frac{L_{\mathrm{m}}}{L_{\mathrm{s}}} R_{\mathrm{s}} i_{\mathrm{qs}}-\omega_{\mathrm{r}} L_{\mathrm{m}} i_{\mathrm{ds}}+\left[\omega_{\mathrm{slip}} L_{\mathrm{r}}-\omega_{\mathrm{s}} \frac{L_{\mathrm{m}}^{2}}{L_{\mathrm{s}}}\right] i_{\mathrm{dr}}
\end{array}\right.
$$




\subsection{Enhanced GSC Control}

During the normal operation, with a reference frame oriented along with the grid voltage vector by the vector control technique, the DC voltage and reactive power from the GSC to the grid are decoupled by controlling $d$ - and $q$-axis components of the line side current. In order to maintain the DC voltage, the active current $i_{\text {gd }}$ should be controlled according to its reference value. As Equation (12) shows, $i_{\mathrm{gd}}$ is proportional to $u_{\mathrm{gq}}$ during the steady-state operation, so $u_{\mathrm{gq}}$ should be kept unchanged during high voltage conditions, $u_{\mathrm{gd}}$ should be added to:

$$
v_{\mathrm{gd}}=\sqrt{V_{\mathrm{glms}, \max }^{2}-v_{\mathrm{gq}}^{2}}
$$

Based on Equation (12), the $i_{\mathrm{gq}}$ reference value should be set to:

$$
i_{\text {gq ref }}=\frac{v_{\mathrm{gd}}-E_{\mathrm{gd}}}{\omega_{\mathrm{s}} L_{\mathrm{g}}}
$$

The load current feed forward control is used to improve the transient performance of the GSC, and reduce the fluctuation of the DC-link voltage of the PWM converter [23]. It is difficult to measure the DC-link current, therefore, the load current $i_{\mathrm{RSC}}$ can be obtained by $\left(P_{\mathrm{r}} / V_{\mathrm{dc}}\right)$, which is expressed as:

$$
i_{\mathrm{RSC}}=\frac{P_{\mathrm{r}}}{V_{\mathrm{dc}}}=\frac{3\left(u_{\mathrm{dr}} i_{\mathrm{dr}}+u_{\mathrm{qr}} i_{\mathrm{qr}}\right)}{2 V_{\mathrm{dc}}}
$$

\section{Case Studies}

The case studies were carried out with a 1.5-MW DFIG WTG to verify the efficacy of the proposed LVRT and HVRT protection schemes, and the enhanced control methods using Matlab/Simulink Simpower Systems. The parameters of the WTG are listed in the Appendix. The threshold of the rotor current to activate the crowbar protection is 2 p.u., and the threshold of the DC voltage to activate the chopper protection is 1.15 p.u., and 1.05 p.u. to deactivate. Three case studies were conducted and compared. The case study scenarios are listed in Table 1. For the case studies, a three-phase fault is applied at $2 \mathrm{~s}$ with $200 \mathrm{~ms}$ duration causing the grid voltage drop of 0.2 p.u. and the voltage swell of 1.3 p.u. during the grid fault recovery (starting at $2.2 \mathrm{~s}$ ).

Table 1. Control schemes for case studies.

\begin{tabular}{cll}
\hline Case & LVRT and HVRT Protection & LVRT and HVRT Control \\
\hline \multirow{2}{*}{1} & Crowbar disabled & RSC without enhanced control \\
& DC_Chopper disabled & GSC without enhanced control \\
2 & Crowbar disabled & RSC with enhanced control \\
& DC_Chopper disabled & GSC with enhanced control \\
\multirow{2}{*}{3} & Crowbar enabled & RSC with enhanced control \\
& DC_Chopper enabled & GSC with enhanced control \\
\hline
\end{tabular}

Figure 11 shows the simulation results of Case 1 which does not have the crowbar or the DC chopper protection scheme or the enhanced converter control schemes. Figure 11a shows the voltage 
profile of the pre-fault, fault and recovery periods. It is shown in Figure $11 \mathrm{~b}, \mathrm{c}$ and $\mathrm{d}$ that the rotor current, stator current and the DC link voltage exceeded the protection settings and the WTG would have tripped due to this.

Figure 11. The responses of the DFIG WTG for case 1: (a) stator voltage; (b) rotor current; (c) stator current; and (d) DC voltage.

(a)

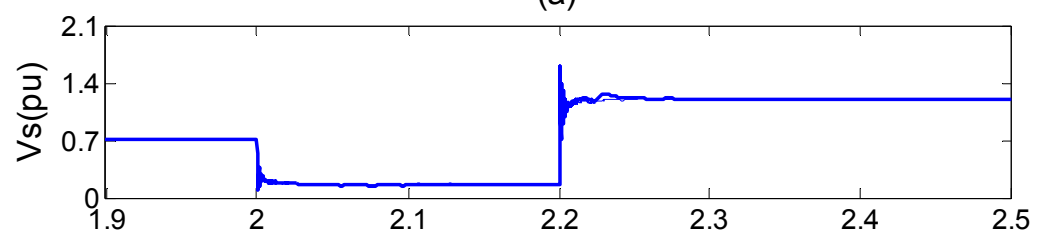

(b)

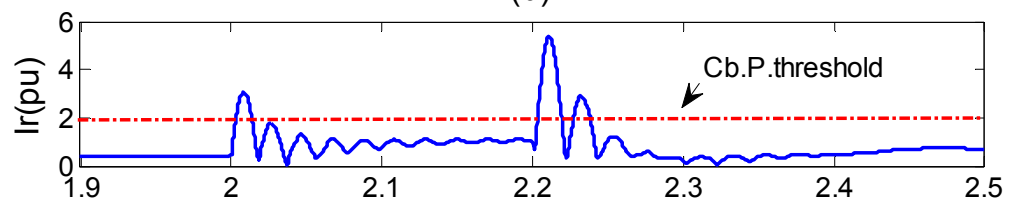

(c)

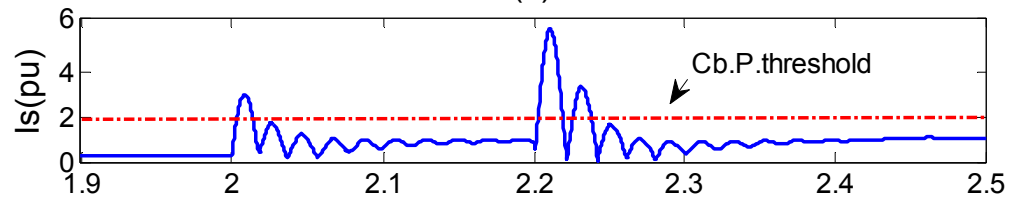

(d)

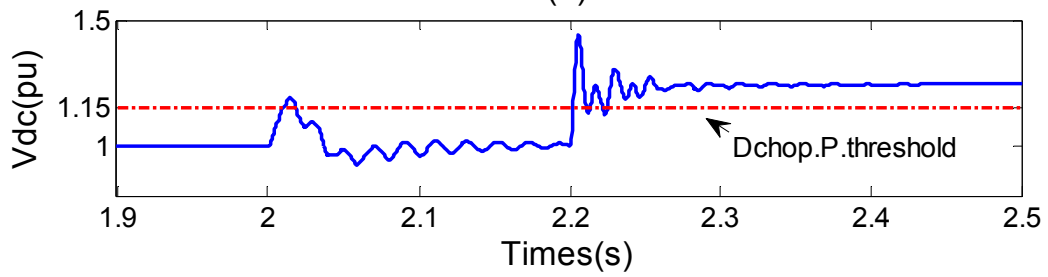

The simulation results of Case 2 are shown in Figure 12. The comparison results of rotor and stator currents with and without the enhanced RSC and GSC control are shown in Figure 12a,b. It is shown that the current overshooting has been reduced by the enhanced RSC and GSC control. The DC link voltage with and without the enhanced RSC and GSC control is shown in Figure 12c and it is shown that the DC link voltage can decrease below the threshold after about $180 \mathrm{~ms}$ from the starting point of the recovery. However, the DC link over-voltage is still an issue.

The DC link voltage and the DC chopper pulse of case 3 are shown in Figure 13. It is shown that the DC link voltage can be kept below the threshold by the combination of the crowbar scheme, and the enhanced RSC and GSC control and the DFIG WTG can successfully ride through the low voltage conditions and the high voltage conditions. 
Figure 12. The responses of the DFIG WTG for case 2. (a) rotor current; (b) stator current; (c) DC voltage.

(a)

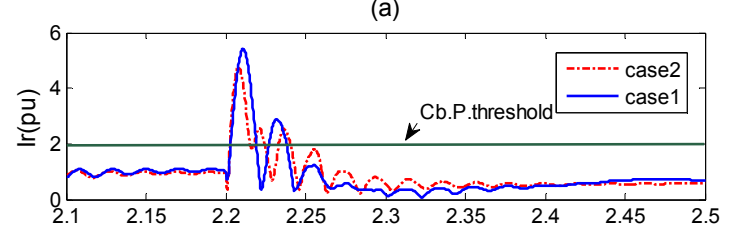

(b)

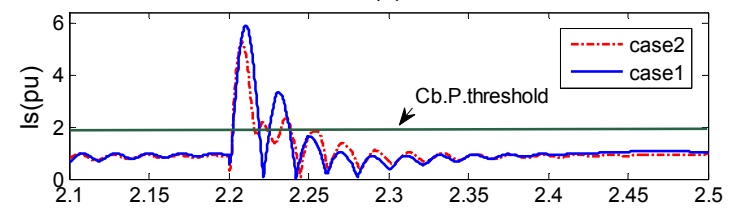

(c)

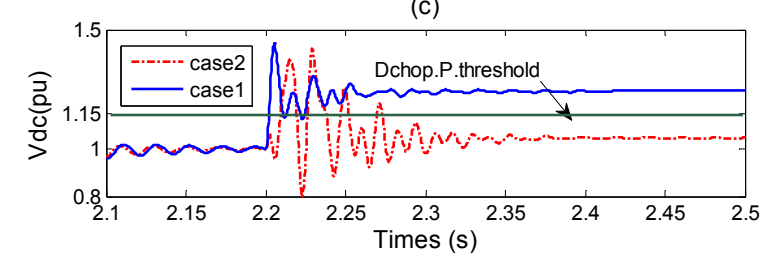

Figure 13. The DC link voltage of case 3: (a) DC voltage; (b) DC chopper circuit control pulses.

(a)

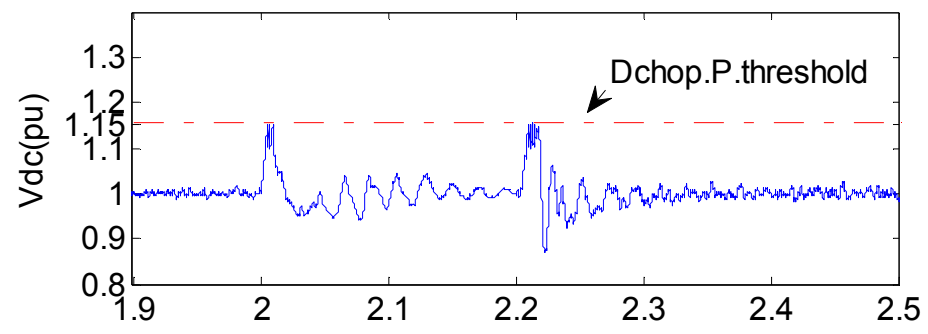

(b)

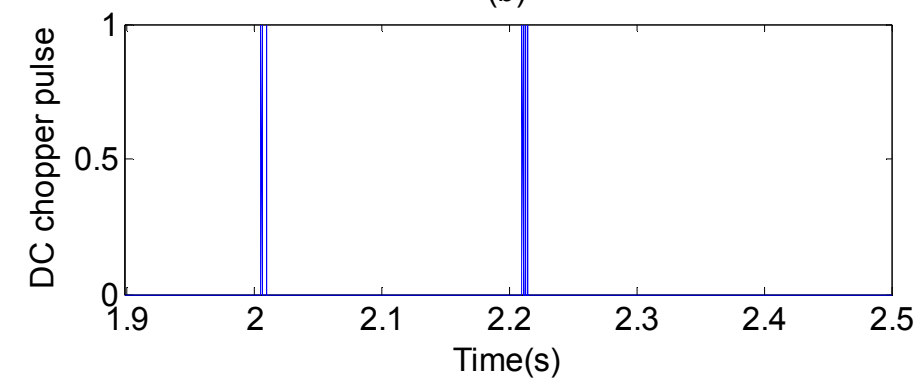

\section{Conclusions}

This paper analyses the transient response of the DFIG WTG with consideration of the phase-angel jump under both grid voltage sag and swell conditions. The rotor crowbar protection scheme coordinated with DC chopper protection scheme is developed to deal with both voltage sag and voltage swell. With the voltage detection method considering the phase-angel jump, the fast coordinated control of the RSC and GSC has been developed. Simulation results show that, by adding the transient stator flux compensation feed-forward factors for the vector control, the transient performance of the RSC controller can be improved. By the reactive current control of the GSC, the DC link voltage can be maintained below the threshold. With the developed crowbar protection scheme, DC chopper 
protection scheme, and the enhanced RSC and GSC control, the DFIG WTG can successfully ride through the continuous low voltage and high voltage conditions.

\section{Acknowledgments}

The authors are grateful to the financial support from the Shenzhen Government through Grant JCYJ20120613170340342 and GJHZ20130408173747552.

\section{Conflicts of Interest}

The authors declare no conflict of interest.

\section{References}

1. Ackermann, T. Wind Power in Power Systems; John Wiley: Chichester, UK, 2005.

2. Tsili, M.; Papathanassiou, S. A review of grid code technical requirements for wind farms. IET Renew. Power Gener. 2009, 3, 308-332.

3. AEMC. National Electricity Rules, Version 59. Available online: http://www.aemc.gov.au/ (accessed on 31 October 2013).

4. Bollen, M.H. Understanding Power Quality Problems: Voltage Sags and Interruptions; IEEE Press: New York, NY, USA, 2000.

5. Bollen, M.H. Algorithms for characterizing measured three-phase unbalanced voltage dips. IEEE Trans. Power Eng. Rev. 2002, 22, 937-944.

6. Mohseni, M.; Islam, S.; Masoum, M.A. Impacts of symmetrical and asymmetrical voltage sags on DFIG-based wind turbines considering phase-angle jump, voltage recovery and sag parameters. IEEE Trans. Power Electron. 2011, 26, 1587-1598.

7. Geng, H.; Liu, C.; Yang, G. LVRT Capability of DFIG-based WECS under asymmetrical grid fault condition. IEEE Trans. Ind. Electr. 2013, 60, 2495-2509.

8. Lopez, J.; Sanchis, P.; Roboam, X.; Marroyo, L. Dynamic behavior of the doubly-fed induction generator during three-phase voltage dips. IEEE Trans. Energy Convers. 2007, 22, 709-717.

9. Lopez, J.; Gubia, E.; Sanchis, P.; Roboam, X.; Marroyo, L. Wind turbines based on doubly fed induction generator under asymmetrical voltage dips. IEEE Trans. Energy Convers. 2008, 23, 321-330.

10. Lopez, J.; Gubia, E.; Olea, E.; Ruiz, J.; Marroyo, L. Ride through of wind turbines with doubly fed induction generator under symmetrical voltage dips. IEEE Trans. Ind. Electr. 2009, 56, 4246-4254.

11. Lima, F.K.A.; Luna, A.; Rodriguez, P.; Watanabe, E.H.; Blaabjerg, F. Rotor voltage dynamics in the doubly fed induction generator during grid faults. IEEE Trans. Power Electr. 2010, 25, 118-130.

12. Mendes, V.F.; de Sousa, C.V.; Silva, S.R.; Cezar Rabelo, B.; Hofmann, W. Modeling and ride-through control of doubly fed induction generators during symmetrical voltage sags. IEEE Trans. Energy Convers. 2011, 26, 1161-1171.

13. Yao, J.; Li, H.; Liao, Y.; Chen, Z. An improved control strategy of limiting the DC-link voltage fluctuation for a doubly fed induction wind generator. IEEE Trans. Power Electr. 2008, 23, 1205-1213. 
14. Conroy, J.F.; Watson, R. Low voltage ride-through of a full converter wind turbine with permanent magnet generator. IET Renew. Power Gener. 2007, 1, 182-189.

15. Okedu, K.E.; Muyeen, S.M.; Takahashi, R.; Tamura, J. Wind farms fault ride through using DFIG with new protection scheme. IEEE Trans. Sustain. Energy 2012, 3, 242-254.

16. Cárdenas, R.; Peña, R.; Alepuz, S.; Asher, G. Overview of control systems for the operation of DFIGs in wind energy applications. IEEE Trans. Ind. Electr. 2013, 60, 2776-2798.

17. Pannell, G.; Atkinson, D.J.; Zahawi, B. Minimum-threshold crowbar for a fault-ride-through grid-code-compliant DFIG wind turbine. IEEE Trans. Energy Convers. 2010, 25, 750-759.

18. Pannell, G.; Zahawi, B.; Atkinson, D.J.; Missailidis, P. Evaluation of the performance of a DC-link brake chopper as a DFIG low-voltage fault-ride-through device. IEEE Trans. Energy Convers. 2013, 28, 535-542.

19. Okedu, K.E.; Muyeen, S.M.; Rion, T.; Junji, T. Protection schemes for DFIG considering rotor current and DC-link voltage. In Proceedings of 24th International Conference Electrical Machines and System (ICEMS), Beijing, China, 20-23 August 2011; pp. 1-6.

20. Hu, S.; Lin, X.; Kang, Y.; Zou, X. An improved low-voltage ride-through control strategy of doubly fed induction generator during grid faults. IEEE Trans. Power Electr. 2011, 26, 3653-3665.

21. Xiao, S.; Yang, G.; Zhou, H.; Geng, H. An LVRT control strategy based on flux linkage tracking for DFIG-based WECS. IEEE Trans. Ind. Electr. 2013, 60, 2820-2832.

22. Liang, J.; Howard, D.F.; Restrepo, J.A.; Harley, R.G. Feed-forward transient current control for low-voltage ride-through enhancement of DFIG wind turbines. IEEE Trans. Energy Convers. 2010, 25, 836-843.

23. Gu, B.G.; Nam, K. A DC-link capacitor minimization method through direct capacitor current control. IEEE Trans. Ind. Appl. 2006, 42, 573-581.

(C) 2014 by the authors; licensee MDPI, Basel, Switzerland. This article is an open access article distributed under the terms and conditions of the Creative Commons Attribution license (http://creativecommons.org/licenses/by/3.0/). 